\title{
A levonorgestrel releasing intrauterine system was more cost effective than was hysterectomy for menorrhagia
}

Hurskainen R, Teperi J, Rissanen P, et al. Quality of life and cost-effectiveness of levonorgestrel-releasing intrauterine system versus hysterectomy for treatment of menorrhagia: a randomised trial. Lancet 2001 Jan 27;357:273-7.

QUESTION: In women with menorrhagia, is the levonorgestrel releasing intrauterine system (IUS) more effective than hysterectomy for quality of life, psychological wellbeing, and cost outcomes?

Design

Randomised (allocation concealed*), unblinded,* controlled trial with 12 months follow up.

Setting

5 university hospitals in Finland.

\section{Patients}

236 women who were 35-49 years of age (mean age 43 y), had menorrhagia, and were eligible for hysterectomy. Exclusion criteria were submucous fibroids, endometrial polyps, ovarian tumors or cysts (diameter $>5 \mathrm{~cm}$ ), cervical disease, urinary and bowel symptoms or pain caused by large fibroids, lack of indication for hysterectomy, history of cancer, menopause, severe depression, metrorrhagia, previous treatment failure with levonorgestrel releasing IUS, severe acne, or uterine malformation. 228 women (97\%) completed the 12 month follow up.

\section{Intervention}

Women were allocated to the levonorgestrel releasing IUS $(n=119)$, which releases $20 \mu \mathrm{g}$ of levonorgestrel over 24 hours for $\geqslant 5$ years from a polydimethylsiloxane reservoir, or to hysterectomy $(\mathrm{n}=117)$, done abdominally, vaginally, or laparoscopically. The mean waiting time for hysterectomy was 6.7 months.

\section{Main cost and outcome measures}

The primary measure of effectiveness was response on the EuroQol (EQ-5D) questionnaire at 12 months. Anxiety, depression, and sexuality related factors were also assessed. Costs measured were hospital services, medication and sick leave and included productivity losses.

\section{Main results}

Analysis was by intention to treat. $20 \%$ of patients in the IUS group had a hysterectomy. At 12 months, the EQ-5D scores improved from baseline $(\mathrm{p}<0.001)$, and the groups did not differ. In all other measures of psychosocial wellbeing, general health, and depression, both groups improved from baseline; groups did not differ except for the pain score on the RAND 36 item health survey that favored hysterectomy $(p=0.01)$. IUS incurred lower costs than hysterectomy (table). When a lower estimate of productivity loss was used, a lower cost was still seen in the IUS group (table).

\section{Conclusion}

In women with menorrhagia, the levonorgestrel releasing intrauterine system was as effective as hysterectomy for outcomes of quality of life and psychological wellbeing and was more cost effective at 1 year.

*See glossary.

Sources of funding: Academy of Finland; STAKES; University Hospitals, Finland. Levonorgestrel releasing IUSs provided by Leiras.

For correspondence: Dr R Hurskainen, STAKES, Box 220, FIN-00531 Helsinki, Finland. Fax +3589 39672485 .

Levonorgestrel-releasing IUS vs hysterectomy for menorrhagia at 12 months†

\begin{tabular}{lll} 
& \multicolumn{2}{l}{ Costs $(95 \% \mathrm{Cl})$} \\
\cline { 2 - 3 } Outcomes (\$U.S.) & IUS & Hysterectomy \\
\hline $\begin{array}{c}\text { Total cost/woman } \\
\text { productivity loss/woman }\end{array}$ & $1530(1203$ to 1853$)$ & $4222(3808$ to 4636$)$ \\
\hline
\end{tabular}

†Costs expressed as US equivalents for Finnish marks ( $\$ 1$ US $=5.89$ Finnish marks).

\section{COMMENTARY}

The use (presumed overuse) of hysterectomy for treatment of idiopathic menorrhagia has been a cause of concern because of potential adverse clinical and economic consequences. Surgical alternatives to hysterectomy (eg, endometrial resection and ablation) have been available for some time, but their use has been limited. Among women awaiting hysterectomy, the levonorgestrel releasing IUS has previously been shown to improve menstrual symptoms and quality of life.

The study by Hurskainen $e t a l$ will encourage patients, consumer groups, third party payers, and government agencies to consider the levonorgestrel releasing IUS as a legitimate therapeutic option in menorrhagia. The evidence shows that the IUS system is more cost effective than hysterectomy. The IUS recipients did not differ from those who received hysterectomy for any health related outcome except that hysterectomy group patients reported less pain. This early evidence needs confirmation of continuing cost effectiveness over a longer period.

The overall aim of management of a chronic, benign condition like menorrhagia is to reduce the adverse effect of the condition on quality of life. This study used only generic quality of life measures to assess outcomes. The additional use of disease specific measures that focus on aspects of health unique to menorrhagia could have strengthened the conclusions even further. Nevertheless, it can be safely inferred that the levonorgestrel releasing IUS is a cost effective treatment for generic health outcomes in menorrhagia in the short term.

Khalid S Khan, MBBS, MSc Birmingham Women's Hospital Birmingham, UK

1 Lahteenmaki P, Haukkamaa M, Puolakka J, et al. Open randomised study of use of levonorgestrel releasing intrauterine system as alternative to hysterectomy. BMJ 1998;316:1122-6. 